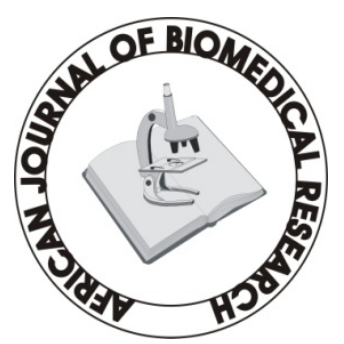

Full-text available at http://www.ajbrui.com http://www.bioline.br/md http://www.ajol.com

Received:

August 2007

Accepted (Revised): December 2007

Published January 2008
Full Length Research Article

\section{Clinical Signs and Organ Pathology in Rats Exposed To Graded Doses of Pyrethroids- Containing Mosquito Coil Smoke and Aerosolized Insecticidal Sprays}

\author{
${ }^{1}$ Taiwo V.O., N.D. Nwagbara ${ }^{1}$, R. Suleiman ${ }^{2}$, J.E. Angbashim ${ }^{1}$ \\ and M.J. Zarma ${ }^{1}$ \\ Departments of ${ }^{1}$ Veterinary Pathology and ${ }^{2}$ Veterinary Physiology \& \\ Pharmacology, University of Maiduguri, Maiduguri. Borno State, Nigeria.
}

\begin{abstract}
Morphological changes in tissues/organs of weanling Albino rats exposed to graded doses of popular brands of pyrethroids-containing insecticides mosquito coil and aerosolized spray were studied over a period of 18 days. Rats were exposed to $0.4,0.8,1.2$ and $1.6 \mathrm{mg} / \mathrm{kg} \mathrm{BW}$ of active ingredients in aerosolized insecticidal spray for 15, 30, 45 and 60 seconds, in two divided doses daily for 18 days. Control rats were not exposed. Early clinical signs include irritability, head shaking and scratching of nostrils; these later gave way to sneezing, gurgling, fine muscular tremors, ruffled fur, lethargy and depression. No self-death was recorded in all the exposed and control groups. Gross changes were not apparent in most organs, but for pulmonary oedema and slight hepatomegaly and palor of kidneys in rats exposed to high doses of the fumes sacrificed on days 12, 15 and 18 post-exposure. Histopathology revealed varying degrees of vacuolar degeneration and necrosis of hepatocyctes, myocardiac degeneration, glomerular and tubular degeneration and necrosis, meningitis, neuronophagia, demyelination of neuronal axons and exudative pnuemonia. Others include blood vascular damage, haemorrhages, vasculitis and thrombosis in many organs, and Kuppfer and intestinal goblet cells hyperplasia. The severity of the lesions was dose and time dependent. The lesions observed suggest interference with tissue energy metabolism and widespread vascular damage and multi-organ degeneration and necrosis. The implications of the consistent and uncontrolled use of pyrethroids-containing insecticides on farm and market produce and in human inhabitants and their effects on public health and biodiversity conservation are discussed.
\end{abstract}

(Afr. J. Biomed. Res. 11: 97 - 104)

Key words: Pyrethroids, insecticides, rats, tissue pathology, public health hazard

*Address for Correspondence; E-mail:victaiwo52@yahoo.com; V.O.T was a visiting staff at the Department of Veterinary Pathology, University of Maiduguri

Abstracted by:

African Index Medicus (WHO), CAB Abstracts, Index Copernicus, Global Health Abstracts, Asian Science Index, Index

Veterinarius, Bioline International , African Journals online 


\section{INTRODUCTION}

Pyrethroids are insecticides chemically similar to pyrethrins found in natural pyrethrum extracted from the flowers of Chrysanthemum cinerariaefolium, known for centuries for their insecticidal activity (CPCN, 2001). They form, together with chlorinated hydrocarbons (DDT, dieldrin, lindane), organo-phosphorus compounds (parathion, malathion, diazinon) and methylcarbamate esters (aldicarb, carbofuran, carbaryl) the four major classes of insecticides (Gassner et al., 1997). First developed in 1973, pyrethroids are more stable to light than natural pyrethrum and possess very good insecticidal activity. The first pyrethroid (fenvalerate) was commercialized in 1978 (WHO, 2005). At present, the class of pyrethroids includes 42 active ingredients, differing in chemical structure or in relative stereoisomer composition (NPTN, 1998). Natural pyrethrins are esters of a cyclopropanecarboxylic acid and a cyclopentenolone alcohol. Structural modifications to one or other of these moieties have produced the diverse pyrethroids that are commercially available as insecticides. Pyrethrin compounds have been used primarily to control human lice, mosquitoes, cockroaches, beetles and flies (Ray, 1991), and additionally in most developing countries, they have been used in grains storage, meat shops, in poultry pens and on dogs and cats to control houseflies especially, and lice and fleas (Gassner et al., 1997).

The use of pyrethroids in the form of mosquito coils and aerosolized insecticidal sprays is on the increase especially in Asia and developing countries of the world (Cheng et al, 1992). Of particular note is the general abuse, wanton overuse of these mosquito coils and insecticidal sprays in the control of mosquitoes, cockroaches and houseflies in most urban and rural dwellings, grain stores, animals and poultry houses and in public places such as fish, meat and vegetable markets. These therefore pose a serious public health and ecological challenge because of the effects associated with their use, especially innocuous and chronic inhalation of the fumes and consumption of produce that may have been laced inadvertently by the chemical constituents of the insecticides.
Global concerns about the hazards associated with the use of pyrethroids have led to regulating bodies such as United States Environmental Protection Agency (1988) and WHO (1967) to label some pyrethroids as "Restricted use pyrethroids" (RUP).

There is paucity of information on the toxicological effects in animals and humans associated with the use of pyrethroids, especially in the form of mosquito coils and insecticidal sprays in a developing country like Nigeria. This study was undertaken to study the tissue/organ morphological changes in rats exposed to graded doses and exposure periods of fumes from popular brands of pyrethroid-containing mosquito coil $(\mathrm{SWAN} \AA)$ and aerosolized insecticidal spray (Baygon ${ }^{\circledR}$ ).

\section{MATERIALS AND METHODS}

\section{Experimental Rats:}

A total of 54 (27 male and 27 female) albino rats (Rattus rattus norwegicus) weanlings aged 12-15 weeks and of average weight of $120 \mathrm{~g}$ were used for the studies. The rats were purchased from the Experimental Animal Unit of the Department of Biochemistry, University of Maiduguri and maintained in the laboratory for 7 days to allow them to acclimatize to their new environment. They were also observed for any ailment that may render them unfit for the study.

\section{Mosquito Coils and Insecticidal Spray:}

The mosquito coils used was SWAN ${ }^{\circledR}$ (Merchant Investors Limited, Chemicals Division, Nigeria). Each coil is $70 \mathrm{~cm}$ long, weighs $12 \mathrm{~g}$ and contains $0.2 \% \mathrm{w} / \mathrm{w}$ composition of d-allethrin, the active ingredient. The insecticidal spray used, Baygon ${ }^{\circledR}$ (Gongoni Company Limited, Nigeria) contains 0.05\% imiprothrin, $0.05 \%$ prallethrin and $.0 .015 \%$ cyfluthrin (all synthetic pyrethrins ) in a $300 \mathrm{ml}$ pressurized liquid canister.

\section{Experimental Design}

The rats were divided into nine groups $(\mathrm{A}, \mathrm{B}, \mathrm{C}$, $D, E, F, G, H$ and $I$ ) of six rats (3 males and 3 females) each. 
African Journal of Biomedical Research 2008 (Vol. 11) / Taiwo, Nwagbara, Suleiman, Angbashim ${ }^{1}$ and Zarma

Table 1: Cumulative doses (mg/kg BW) of pyrethroid-containing fumes from smouldering mosquito coils and aerosolized insecticidal sprays to which the rats were exposed

\begin{tabular}{|c|c|c|c|c|c|c|c|c|}
\hline \multirow{2}{*}{$\begin{array}{l}\text { Exposure } \\
\text { period } \\
\text { (days) }\end{array}$} & \multicolumn{8}{|c|}{ GROUP } \\
\hline & $\mathbf{A}^{*}$ & B & C & D & $\mathbf{E}$ & $\mathbf{F}$ & G & $\mathbf{H}$ \\
\hline 3 & 5.4 & 10.8 & 16.2 & 21.6 & 0.40 & 0.80 & 1.20 & 1.60 \\
\hline 6 & 10.8 & 16.2 & 21.6 & 27.0 & 0.80 & 1.20 & 1.60 & 2.00 \\
\hline 9 & 16.2 & 21.6 & 27.0 & 32.4 & 1.20 & 1.60 & 2.00 & 2.40 \\
\hline 12 & 21.6 & 27.0 & 32.4 & 37.8 & 1.60 & 2.00 & 2.40 & 2.80 \\
\hline 15 & 27.0 & 32.4 & 37.8 & 43.2 & 2.00 & 2.40 & 2.80 & 3.20 \\
\hline 18 & 32.4 & 37.8 & 43.2 & 48.6 & 2.40 & 2.80 & 3.20 & 3.60 \\
\hline
\end{tabular}

*Rats in Groups $A, B, C$ and $D$ were exposed to d-allethrin in smouldering mosquito coils; while those in Groups $E$, $F, G$ and $H$ were exposed to synthetic pyrethroids in insecticidal spray.

For the mosquito coils experiment, each group of rats $(\mathrm{A}, \mathrm{B}, \mathrm{C}$ and $\mathrm{D})$ was housed in a perforated paper board carton $(90 \mathrm{~cm} \times 60 \mathrm{~cm} \times 60 \mathrm{~cm})$, in order to provide reasonable aeration, since the fumes are heavier than air. They were then exposed to calculated doses of 5.4, 10.8, 16.2 and $21.6 \mathrm{mg} / \mathrm{kg}$ bodyweight (BW) of the active ingredient (d-allethrin) in the fumes from smouldering mosquito coils for 15, 30, 45 and 60 minutes, in two divided doses daily (morning and evening) for 18 days. Rats in groups E, F, G and $\mathrm{H}$ (the insecticidal spray groups) were exposed to $0.4,0.8,1.2$ and $1.6 \mathrm{mg} / \mathrm{kg}$ BW respectively, of the combined active ingredients (imiprothrin, prallethrin and cyfluthrin) in sprayed puffs from the aerosolized insecticide for 15, 30, 45 and 60 seconds, also in two divided doses daily for 18 days in air-tight plastic boxes $\left(0.75 \mathrm{~m}^{3}\right)$ in a separate location away from the A, B, C and D groups. Rats in group I served as unexposed controls housed in standard rat boxes placed in a location away from the other two groups. This was done to prevent possible double or unexpected exposure of test and control rats. All the rats were fed with standard commercial rat pellets and water was provided ad libitum throughout the experiment. Table 1 shows the cumulative doses of the active ingredients of the fumes that rats in each group were exposed to during the study period.

The rats in each group were observed for any clinical signs associated with the exposure to the active ingredients from the fumes, especially immediately after each exposure period. One rat from each group was sacrificed by exsanguination after every 3 days of exposure and the lungs, livers, kidneys, spleens, hearts, intestines and brains were observed for any gross lesions. Samples from each organ were collected and fixed in $10 \%$ phosphate-buffered formalin for 24 hours. The organs were routinely processed and $5 \mu \mathrm{m}$ thick sections were stained with haematoxylin and eosin and observed for histolopathological changes under the light microscope.

\section{RESULTS}

\section{Clinical Signs and Organ Pathology}

The very early clinically signs include irritability, scratching of nostrils and head shaking. The rats exposed to high doses of the fumes exhibited more pronounced signs. In the later stages, from day 9 onwards, the clinical signs became more severe and in addition there were sneezing, gurgling, fine muscular tremors, ruffled fur, lethargy and depression. None of the exposed and control rats died throughout the period of the experiment.

Gross pathological changes were not apparent in most organs except for varying degrees of darkened lungs, pulmonary oedema (wetness of the lungs and presence of froth in tracheae and bronchi) and slight hepatomegaly and palor of kidneys in rats exposed to high doses of the fumes and sacrificed on days 12, 15 and 18 postexposure. 
Table 2:

Organ/tissue pathology scores of rats exposed to varying doses of pyrethroids from mosquito coils and insecticidal spray fumes

\begin{tabular}{|c|c|c|c|c|c|c|c|c|}
\hline \multirow[b]{2}{*}{ ORGAN LESIONS } & \multicolumn{8}{|c|}{ RAT GROUPS $^{*}$} \\
\hline & $\mathbf{A}$ & B & $\mathrm{C}$ & $\mathbf{D}$ & $\mathbf{E}$ & $\mathbf{F}$ & $\mathbf{G}$ & $\mathbf{H}$ \\
\hline \multicolumn{9}{|l|}{ Liver } \\
\hline $\begin{array}{l}\text { Vacuolar degeneration } \\
\text { and }\end{array}$ & + & + & ++ & ++ & ++ & ++ & ++ & +++ \\
\hline \multicolumn{9}{|l|}{ Thrombosis and vasculitis } \\
\hline \multicolumn{9}{|l|}{ Heart } \\
\hline $\begin{array}{l}\text { Congestion/haemorrhage } \\
\text { Vacuolar degeneration }\end{array}$ & \pm & + & + & ++ & \pm & + & ++ & ++ \\
\hline and necrosis & + & + & + & ++ & + & ++ & +++ & +++ \\
\hline Thrombosis and vasculitis & \pm & + & + & ++ & + & \pm & ++ & ++ \\
\hline \multicolumn{9}{|l|}{ Lungs } \\
\hline Exudative pneumonia & \pm & + & ++ & +++ & \pm & + & + & ++ \\
\hline Anthracosis & \pm & + & ++ & ++ & - & - & - & - \\
\hline $\begin{array}{l}\text { Thrombosis } \\
\text { vasculitis }\end{array}$ & \pm & \pm & + & ++ & + & + & ++ & ++ \\
\hline
\end{tabular}

\section{Kidney}

Glomerular and tubular degeneration and necrosis Thrombosis and vasculitis \pm

\section{$\underline{\text { Brain }}$}

Congestion/ haemorrhage

Neuronal degeneration

and

spongiosis

Thrombosis and vasculitis

\section{Small Intestine}

Congestion/haemorrhage \pm Thrombosis and vasculitis -

Goblet cell hyperplasia

$\pm$

$\begin{array}{llll}++ & + \\ + & +\end{array}$

$++\quad++$

$+\quad++$

$\pm$

$+$

$+$

$++$

$++$

$+++$

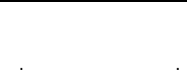

$+\quad++\quad+$

$\pm \quad+$

$++\quad++$

* Rats in Groups A, B, C and D were exposed to graded doses of d-allethrin in smouldering mosquito coils; while those in Groups E, F, G and H were exposed to graded doses of pyrethroids in insecticidal spray as shown in Table 1

Key to scores:-

$-\quad=$ No lesions observed; $\pm \quad=$ Mild, focal lesions; $+=$ Moderate, multifocal lesions;

$++\quad=$ Moderately severe, diffuse lesions; $+++=$ Very severe, diffuse lesions

Histopathology (Table 2) revealed varying degrees of vacuolar degeneration and necrosis of hepatocyctes (Fig. 1), vacuolar degeneration necrosis of myocardial fibres (Fig.2), renal glomerular and tubular degeneration and necrosis (Fig. 3), meningitis, neuronal degeneration, neuronophagia and spongiosis (Fig. 4), anthracosis and exudative pneumonia (Figs. $5 \& 6$ ). There 
were blood vascular damage, haemorrhages, vasculitis and thrombosis in many organs, and Kuppfer and intestinal goblet cells hyperplasia. The most severe lesions were observed with rats exposed to high dosages and increasing times of exposure to the pyrethroid compounds.

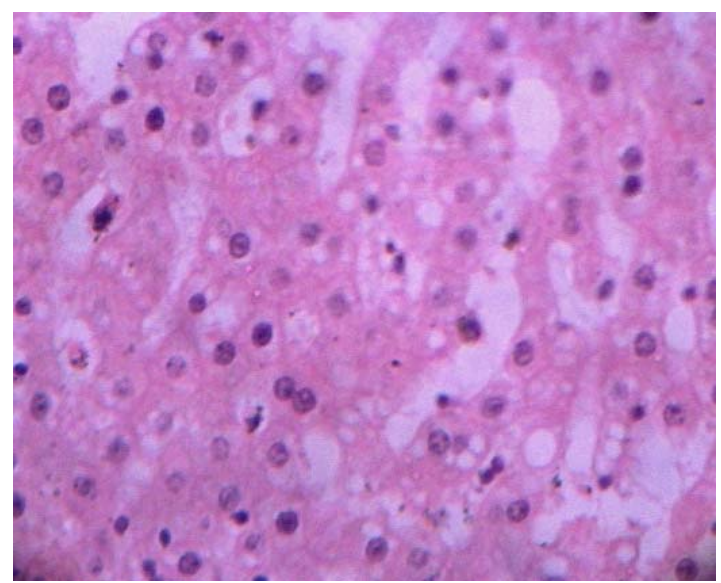

Plate 1.

The liver of albino rat exposed to $34.20 \mathrm{mg} / \mathrm{kg}$ BW of dallethrin in mosquito coil fumes for 12 days showing severe widespread vacuolar degeneration and necrosis of hepatocytes (H \& E; x450)

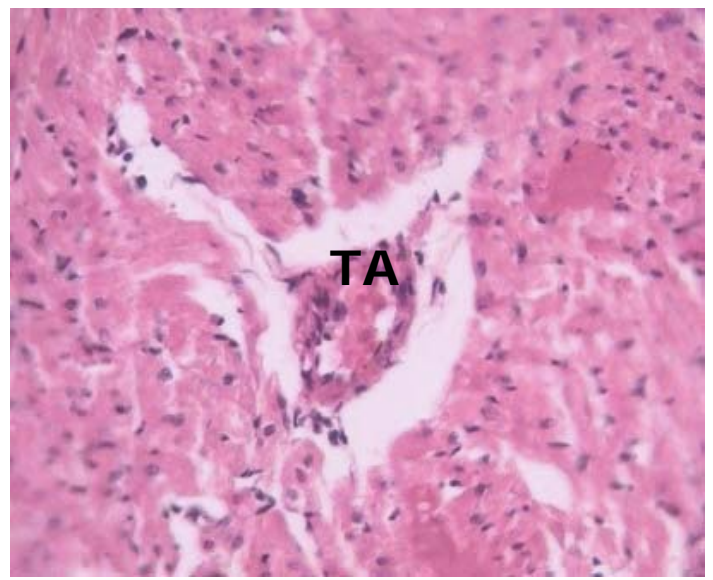

\section{Plate 2}

The heart of albino rat exposed to $2.40 \mathrm{mg} / \mathrm{kg}$ BW of pyrethroids in aerosolized insecticidal spray for 12 days showing vacuolar and hyaline degeneration of myocardiac fibres, mononuclear cell infiltration, vasculitis and thrombosis of an artery (TA) (H \& E; $\mathrm{x} 450$ )

\section{DISCUSSION}

The results obtained from these experiments have shown that acute and chronic exposure to synthetic pyrethroids in mosquito coils (dallethrin) and insecticidal sprays (imiprothrin, prallethrin and cyfluthrin) are toxic to rats in a dose and exposure period dependent manner. The clinical signs observed in this study were mostly nervous and respiratory in manifestation: irritability, head shaking, scratching of nostrils, sneezing, gurgling, fine muscular tremors, ruffled fur, lethargy and depression and these are consistent with previous reports (OHS, 1987; EXTOXNET, 1994a, b). None of the exposed or control rats died during the study. This may be attributable to the very low dose, $\leq 10 \%$ of the $\mathrm{LD}_{50}$ for rats (OHS, 1987). Also, pyrethroids do not accumulate in the body; have very rapid excretion, even after repeated administrations (Aldridge, 1990; IPCS, 1990; Vijverberg and van den Bercken., 1990).

The major pathological changes in the organs of the exposed rats are widespread vascular damage, vascultis, haemorrhage, thrombosis, multi-organ degeneration and necrosis, with the most severe lesions recorded in rats exposed to fumes from the aerosolized insecticidal spray for $>12$ days.

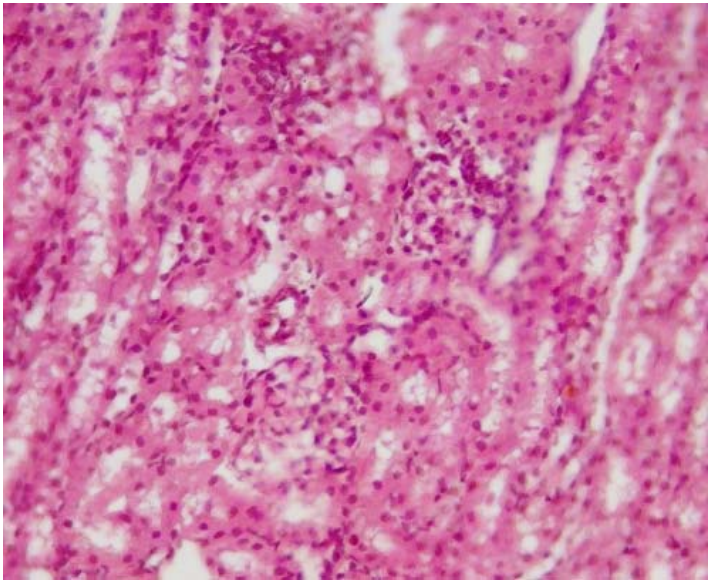

Fig. 3:

The kidney cortex of albino rat exposed to $16.2 \mathrm{mg} / \mathrm{kg}$ BW of d-allethrin in mosquito coils fumes for 6 days showing glomerular and vacuolar tubular degeneration and necrosis, and mild interstitial mononuclear cell infiltration (H \& E; x450) 


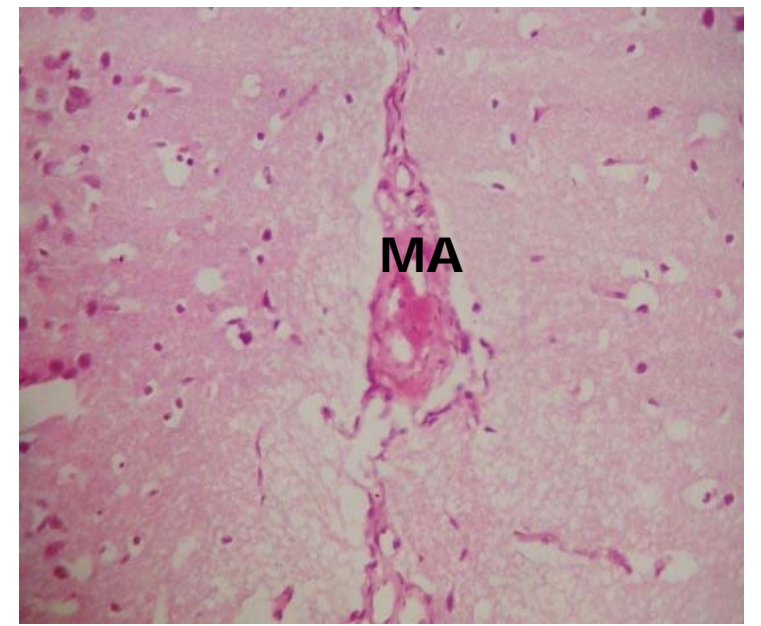

Fig. 4:

The cerebrum of albino rat exposed to $2.8 \mathrm{mg} / \mathrm{kg}$ of pyrethroids from aerosolized insecticidal spray for 12 days showing fibrinoid degeneration and thrombosis of a meningeal arteriole (MA), moderate neuronal degeneration, neuronophagia and mild spongiosis ( $\mathrm{H}$ \& $\mathrm{E} ; \mathrm{x} 450)$

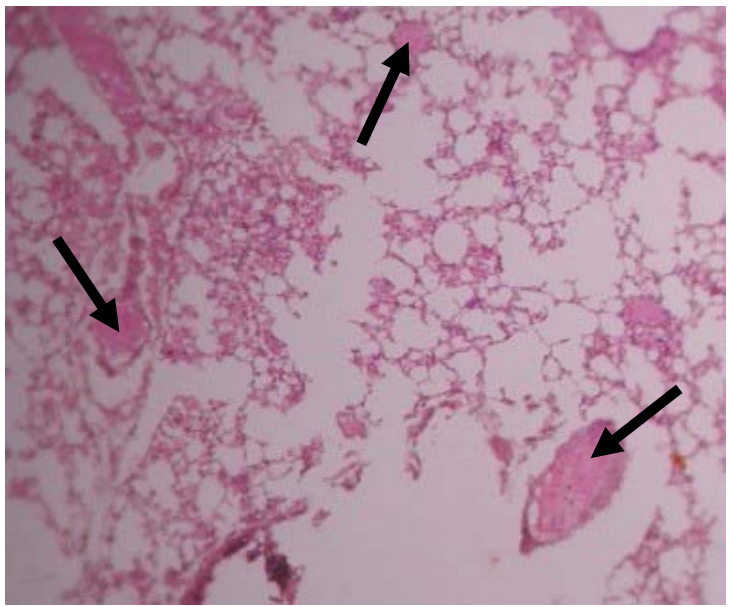

Fig. 5:

The lung of albino rat exposed to $2.00 \mathrm{mg} / \mathrm{kg}$ BW of pyrethroids from aerosolized insecticidal spray for 9 days showing moderate thickening of interalveolar septa and multiple thrombosis of blood vessels (arrows) (H \& E; x450)

This is quite interesting as the dosages of the combined pyrethroids (imiprothrin, prallethrin and cyfluthrin) to which these rats were exposed, were 10 times lower and time of exposure much shorter than those rats exposed to d-allethrin in mosquito coils. This may be due to a more efficient active ingredient delivery associated with aerosolized sprays and the additive effect(s) of the solvent carrier of the active ingredients, which are mostly butanol, dimethylether, xylene, methyl paraben and aldehydes (Righi and Palermo-Neto, 2003). It is noteworthy that both fumes were administered by inhalation. However, oral, cutaneous and conjunctival absorption of these fumes can not be ruled out, as these substances are known to be deposited on skin and fomites in areas where they are applied.

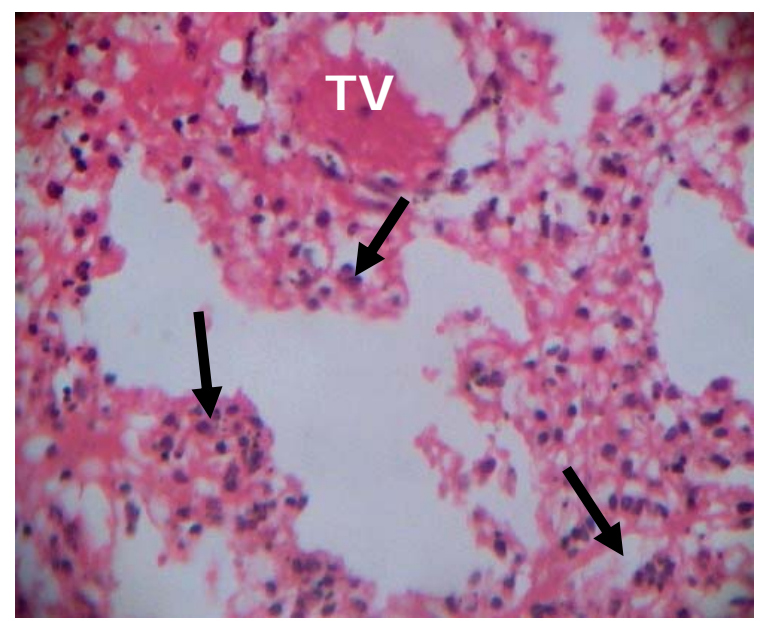

Fig. 6:

The lung of albino rat exposed to $27.00 \mathrm{mg} / \mathrm{kg}$ of dallethrin in mosquito coil fumes for 9 days showing thickened interalveolar septa and thrombosis of a venule (TV). Note alveolar macrophages laden with phagocytosed carbon particles (anthracosis; Arrows) (H \& E; $\mathrm{x} 450$ )

Anthracosis was observed in rats exposed to fumes from smouldering mosquito coils, but not in rats exposed to fumes from the aerosolized insecticidal spray. The implication of this is that binding materials included in the mosquito coils contain carbon and other sundry compounds. Liu et al. (2003) reported that exposure to the smoke of mosquito coils pose significant acute and chronic health risks to humans. Burning one mosquito coil would release the same amount of particulate matter $<2.5 \mu \mathrm{m}$ in diameter $\left(\mathrm{PM}_{2.5}\right)$ mass as burning 75-137 cigarettes and the emission of formaldehyde from burning one coil can be as high as that released from burning 51 cigarettes (Liu et al., 2003).

The natural pyrethrins are contact poisons 
which quickly penetrate the nervous system of the insect, and in a few minutes after application, the insect is "knocked down" and cannot move or fly away (Gassner et al., 1997; Moschetti, 2002). Based on the symptomology after acute intoxication of insects and mammals, they fall into two classes: type I, non- $\ltimes$-cyano-pyrethroids, such as permethrin which show generally peripheral activities and type II pyrethroids, such as cyhalothrin, with an incline to central cyano-action (Leahey, 1985). They are also potent inhibitors of the mitochondria complex I (Gassner et al, 1997), oxygen consumption (Gosh 1989, Reddy and Philip, 1992), hence they inhibit the production of adenine triphosphate (ATP) in the mitochondria of cells. This leads to the alteration of the $\mathrm{Na}^{+} / \mathrm{K}^{+}$ pump kinetics, a principal molecular mode of action of synthetic pyrethroids (Vijverberg et al., 1982; Vijverberg and van den Bercken, 1990; Tatebayashi and Narahashi, 1994). There is sodium and water transport into the cell cytosol, cellular water overload, deranged protein synthesis and mechanical function (Guyton and Hall, 2000).

Accumulation of phospholipids, fatty acids and cholesterol within the cell due to inability of the mitochondria top utilize them for ATP production results in fatty degeneration of parenchymal cells. This could be responsible for vacuolar degeneration and necrosis observed in the liver, kidney, lung, heart and brain of rats exposed to these synthetic pyrethroids. The endothelium, being a versatile tissue of high metabolic activity, is also similarly affected, hence vascular damage, vascultis, thrombosis and ischaemic necrosis which are the hallmark of the lesions in all the organs of the exposed rats. It is in fact, the major pathogenetic pathway of multiple organ pathology in this study.

Synthetic pyrethroids are widely used in agriculture. They are increasingly being used in veterinary applications on farm and pet animals for the protection of stored foodstuffs, control of endemics and parasites in public health programs as well as for household applications in kitchens and bedrooms. Specifically in indoor applications, market stalls, where they are used to control mosquitoes, cockroaches and houseflies, a sustained contamination results from the adsorption of pyrethroids to small dust particles, merchandise such as meat, fish and vegetables, and various other surfaces (Schwabe et al., 1994; Wiles and Davies, 1995; FDA/CSFAN, 1998). The findings from the present study suggest that exposure to the smoke of mosquito coils similar to the tested ones can pose significant acute and chronic health risks, not different from those from cigarette smokes (Liu et al., 2003). Chronic exposure of human, animals and untargeted, but "useful" insects and other organisms to low doses of synthetic pyrethroids consequently results, leading to morbidities, reproductive problems and mortalities (He et al, 1989; Eil and Nisula, 1990; WHO, 2005).

Based on clinical analyses, Müller-Mohnssen and Hahn (1995) and Degli Esposti et al. (1996) postulated causative links between the exposure to synthetic pyrethroids and the development of motor and sensory disorders, including Parkinsonlike syndromes and insulin-dependent diabetes mellitus, respectively. Synthetic pyrethroid insecticides may therefore represent an important indoor and environmental toxin, causing unquantifiable economical, ecological and biodiversity imbalance. Hence, pragmatic legislative and regulatory machinery by the National Foods, Drug Administration and Control and Federal Department of Pest Control Services, that will guide the importation and use of these pyrethroids, in whatever form, is advocated.

\section{REFERENCES}

Aldridge, W.N. (1990). An assessment of the toxicological properties of pyrethroids and their neurotoxicity. Toxicology 21: $89-104$.

Cheng, V, Lee, H.R. and Chen, C.S. (1992). Morphological changes in the respiratory system of mice after inhalation of mosquito coil smoke. Toxicol. Lett. 62: 163 - 177.

CPCN (2001). Compendium of Pesticide Common Names. Pyrethroid insecticides - http://www.hclrss. demon.co.uk .

Degli Esposti, M., Ngo, A. and Myers, M.A. (1996): Inhibition of mitochondrial complex I may account for IDDM induced by intoxication with the rodenticide Vacor. Diabetes 45: 1531-1534.

Eil, $C$ and Nisula, B.C.(1990). The binding 
properties of pyrethroids to human skin fibroblast androgen receptors and to sex hormone binding globulin. J. Steroid Biochem 35: 409 - 414.

EXTOXNET, Extension Toxicology NetworkPesticide Information Profiles (1994a). Pyrethrins and Pyrethroids http://ace.orst.edu/info/extoxnet/ghindex.html

EXTOXNET, Extension toxicology networkpesticide information profiles (1994b). Cyfluthrin. http://ace.orst.edu/info/extoxnet/ghindex.html

FDA/CFSAN (1998). Food and Drug Administration./Center Food Safety and Applied Nutrition Pesticide program: Residue Monitoring 1996. http://vm.cfsan.fda.gov.

Gassner, B, Andreas, W, Gunter, S and Solioz, $M$. (1997). The pyrethroids permethrin and cyhalothrin are potent inhibitors of mitochondrial complex I. $J$. Exp.Pharmacol. 281: 855 - 860.

Ghosh, T. K. (1989). Influence of cypermethrin on the oxidative metabolism of Labeo rohita. Proc. Ind. Natl. Sci. Acad. B55: 115-120.

Guyton, A.C and Hall, J.E (2000). Text book of Medical Physiology. 10 ${ }^{\text {th }}$ edition. pp. $14-20$.

He F, Wang S, Liu L, Chen S, Zhang Z, Sun J. (1989). Clinical manifestations and diagnosis of acute pyrethroid poisoning. Arch Toxicol. 63: 54-58.

IPCS (1990). International Programme on Chemical Safety. Cyhalothrin. Environmental Health Criteria 99. Geneva, World Health Organization.

Leahy, J.P. (1985). The pyrethroid insecticides. Taylor and Francis. London and Philadelphia.

Liu, W., Zhang, J. Hashim, J.H., Jalaludin, J., Hashim, Z., and Goldstein, B.D. (2003). Mosquito coil emissions and health implications. Environ. Health Perspect. 111: 1454-1460. http://dx.doi.org/.

Moschetti, R. (2002), Integrated Pesticides Management of Alaska. P.O. Box 875006 Wasilla, Alaska 99687. http://ipmofalaska.homestead.com/ untitled1.html

Müller-Mohnssen, H. and Hahn, K. (1995). Ueber eine Methode zur Früherkennung neurotoxischer Erkrankungen am Beispiel der Pyrethroidintoxikation. Gesundheitsw. 57: 214-222.

NPTN (1998). National Pesticide Telecommunications Network. Fact Sheets (1998). Pyrethrins and Pyrethroids. http://npic.orst.edu/factsheets/pyrethrins.pdf. OHS (1987). Occupational Health Services Inc Pyrethrum. Material Safety Data Sheet. New York.

Ray, D.E. (1991). Pesticides derived from plants and other organisms in Hayes, W.J, Wayland,

Reddy, P.M and Philip, H. (1992). Changes in the levels of respiration and ions in the tissue of fresh water fish, Labeo rohita under fenvalerate stress. Chemosphere 25: $843-852$.

Righi, D.A., Palermo-Neto, J. (2003). Behavioural effects of type II pyrethroid cyhalothrin in rats. Toxicol. Appl. Pharmacol. 191: 167-176.

Schwabe, R., Becker, K., Class, T., Eckrich, W., Hoffmann, G., Hoppe, H. W., Krause, C., Preiss, A., Riegner, K., Schäffer, K., Schulz, C., Stolz, P. and Walker, G. (1994). Pyrethroide im Hausstaub. Eine Uebersicht. WaBoLu Hefte 3: 1-111.

Tatebayashi, $H$ and Narahashi, T. (1994). Differential mechanism of action of the pyrethroid tetramethrin on tetrodotoxin-sensitive and tetrodotoxin-resistant sodium channels. J. Expt. Pharmacol. 270: 595 - 603.

USEPA (1988). United States Environmental Protection Agency. Pesticide Fact Sheet; No.193. Washington D.C.

Vijverberg, H.P.M and Van Den Bercken, J. (1990). Neurotoxicological effects and the mode of action of pyrethroids insecticides. Crit. Rev. 21: 105 $-126$.

Vijverberg, H.P.M, Van Der Zalm, J.M and Van Den Bercken, J. (1982). Similar mode of action of pyrethroids and DDT on sodium channel gating in myelinated nerves. Nature 295: 601- 605.

WHO (1967). Safe Use of Pesticides in Public Health. WHO Technological Report Series No. 356, Geneva, Switzerland.

WHO (2005). World Health Organization.Safety of Pyrethroids for Public Health Use. WHO/CDS/WHOPES/GCDPP/2005.10.

Wiles, $R$ and Davies, K. (1995). Pesticides in baby food. Environmental working group and National Campaign for Pesticide Policy Reform. Washington D.C. 